NASA

Technical Memorandum 102392
AVSCOM

Technical Memorandum 89-C-012

\title{
Elasticity Effects on Cavitation in a Squeeze Film Damper Undergoing Noncentered Circular Whirl
}

David E. Brewe

Propulsion Directorate

U.S. Army Aviation Research and Technology Activity-AVSCOM

Lewis Research Center

Cleveland, Ohio

Presented at the

Nordic Symposiūm on Tribology

sponsored by Wear Magazine

Trondheim, Norway, June 26-29, 1988

\section{N/SA}

(NASA-TM-102392) ELASTICITY EFFECT
CAVITATION IN A SQUEEZE FILM DAMPER

CAVITATION IN A SQUEEZE FILCULARPER WHIRL

UNDERGOING NONCENTERED CIOCULAR WHIRL CSCL 131

(NASA) $20 \mathrm{P}$

$63 / 37 \quad 0243251$ 
. 
ELASTICITY EFFECTS ON CAVITATION IN A SQUEEZE FILM DAMPER UNDERGOING

NONCENTERED CIRCULAR WHIRL

David E. Brewe

Propulsion Directorate

U.S. Army Aviation Research and Technology Activity - AVSCOM

Lewis Research Center

Cleveland, Ohio 44135

\section{ABSTRACT}

Elasticity of the liner and its effects on cavitation were numerically determined for a squeeze film damper subjected to dynamic loading. The loading was manifested as a prescribed motion of the rotor undergoing noncentered circular whirl. The boundary conditions were implemented using Elrod's algorithm which conserves lineal mass flux through the moving cavitation bubble as well as the oil film region of the damper. Computational movies were used to analyze the rapidly changing pressures and vapor bubble dynamics throughout the dynamic cycle for various flexibilities in the damper liner. The effects of liner elasticity on cavitation were only noticeable for the intermediate and high values of viscosity used in this study.

\section{INTRODUCTION}

Earlier work by Jacobson and Hamrock (Refs. I and 2) using high-speed photography revealed the existence of vapor cavitation in dynamically loaded journal bearings. A polymethylmethacrylate (PMMA) housing was used for visualization of the cavitation. In their studies they investigated the effect of roller material, the influence of $L / D$, effect of static and dynamic eccentricities and influence of speed. A theoretical model implementing the Elrod algorithm (Ref. 3) was developed by Brewe (Ref. 4) for the dynamically loaded journal bearing. The algorithm conserves mass throughout the computational domain and essentially mimics the Jakobsson-Floberg and olsson boundary conditions (Refs. 5 and 6 ). Later some of the earlier experiments 
were used to corroborate the theoretical model (Ref. 7). A prediction of 32 ms bubble life for nonstationary cavitation was obtained from the theoretical model. Using high-speed photography for the same set of conditions, a bubble life of 23 ms was observed in the laboratory. This discrepancy was attributed to deformation and temperature effects as well as some uncertainty in correlating actual life with duration of visibility. To achieve a more representative comparison it is necessary to include the thermal effects in the model as well as deformation of the shaft and housing. This analysis represents a first step toward including first-order deformation effects with the Elrod algorithm. As such the model assumes that the bearing is essentially a thin tube surrounded by a rigid housing. Since the periphery of the bearing is much larger than its thickness, the radial deformations of the latter at a point may be assumed to be proportional to the pressure at the point. This model is commonly referred to as the Winkler foundation and has been used by numerous investigators, i.e., (Refs. 8 to 12). At approximately the same time that Dowson and Taylor (Ref. 9) published their work for a compliant thrust bearing application, Castelli, et al. (Ref. 13) published their findings using an exact analytical approach. In this paper and in a discussion to the Dowson paper (Ref. 9), the limitations of the Winkler foundation are discussed. Based on this, the thin liner materials used in this investigation appear to be suited to the assumptions of the theory. Realistic edge effects are not expected however.

The purpose of this paper is to study the elastic effects of the bearing liner on cavitation in a squeeze film damper. It has been shown for steadily loaded bearings that increasing the liner flexibility increases the cavitation angle (Refs. 14 to 17) using Reynolds boundary conditions. It is believed that under dynamic conditions the elasticity of the liner may influence the 
bubble dynamics and hence the damping characteristics of the squeeze film damper.

\section{NOMENCLATURE}

B parameter, $\frac{6 n \omega_{d} d}{\left(\Delta R / R^{3}\right) E R}\left(1-\frac{2 \sigma^{2}}{1-\sigma}\right)$

D shaft diameter, $m$

d thickness of the bearing liner, $m$

E Youngs Modulus, $\mathrm{N} / \mathrm{m}^{2}$

e eccentricity, m

g switch function, cavitation index

$H$ dimensionless film thickness, $h / \Delta R$

h film thickness, m

$L$ length of the bearing, $m$

$L / D$ length to diameter ratio

in lineal mass flux, $\mathrm{kg} \mathrm{m}^{-1} \mathrm{~s}^{-1}$

p fluid pressure, $\mathrm{N} \mathrm{m}^{-2}$

$\mathrm{pa}$ ambient pressure, $\mathrm{N} \mathrm{m}^{-2}$

$\mathrm{P}_{\mathrm{C}}$ cavitation pressure, $\mathrm{N} \mathrm{m}^{-2}$

$\bar{p}$ dimensionless pressure, $\frac{(\Delta R / R)^{2} p}{6 n \omega_{d}}$

$R$ radius of shaft, $m$

$t$ time, s

$U$ sum of the surface velocities in $x$ direction, $m s^{-1}$

$v$ sum of the surface velocity vectors, $\mathrm{m} \mathrm{s}^{-1}$

W load capacity, $N$

$\bar{w}$ dimensionless load capacity, $\frac{(\Delta R / R)^{2} W}{6 n \omega_{d}}$ 
B liquid bulk modulus, $\mathrm{N} \mathrm{m}^{-2}$

$Y$ angular position of minimum film, rad

$\Delta \quad$ dimensionless radial deflection; $\delta / \Delta R$

$\Delta R \quad$ radial clearance, $m$

$\delta$ radial deflection, $m$

$\varepsilon \quad$ eccentricity ratio, e/ $\Delta R$

$\theta$ fractional film content in cavitation zone; density ratio $\left(\rho / \rho_{C}\right)$ in full fi Im zone

$\mu \quad$ dynamic viscosity, $N \leqslant m^{-2}$

$\rho$ fluid density within full film zone, $\mathrm{kg} \mathrm{m}-3$

$\rho_{C} \quad$ fluid density within cavitated zone, $\mathrm{kg} \mathrm{m}^{-3}$

$\varphi$ angular coordinate relative to minimum film line, rad

wd orbital angular velocity of journal center about fixed point relative to housing center, rad $\mathrm{s}^{-1}$

$\omega_{s}$ angular velocity of journal about its own center, rad $s^{-1}$

\section{THEORY}

\section{Cavitation Algorithm}

A computer program was developed based on Elrod's algorithm (Ref. 3) that combines a control volume approach to deriving the finite-difference equation with a switching function that automatically handles the moving boundary condition at the liquid-vapor interface. The complication in satisfying the boundary condition is avoided by defining a single independent parameter $\theta$ which links the full-film region and the cavitated region. This parameter is defined by the ratio of the local density to that of the cavitation density, i.e.,

$$
\theta=\frac{\rho}{\rho_{C}}
$$


It follows that in the cavitation region $\theta<1.0$ and in the full-film region $\theta>1.0$. A switch function $g$ was defined as "on" $(g=1)$ and "off" $(g=0)$ in the full-film and cavitation regions respectively. By using this property, a universal Reynolds equation was defined as indicated:

$$
\frac{\partial(p h)}{\partial t}+\vec{\nabla} \cdot \dot{m}=0
$$

where $\dot{m}$ represents the lineal mass flux and is given by

$$
\frac{\dot{m}}{\rho_{c}}=\frac{\theta h \vec{V}}{2}-\frac{h^{3}}{12 \mu} \beta g(\theta) \vec{\nabla} r
$$

In the cavitation region, the second term vanishes since $g=0$. This equation was integrated in time by using an Euler's method to advance in time. At every time step the difference equation was solved by an Alternating Direction Implicit (ADI) scheme. The switch function was updated after each half-time step. Occasionally, during the collapse of the vapor bubble, liquid was piling up at the boundary. This was due to an inherent time lag of the switch function with the calculation. Consequently, the switch function was immediately updated to accommodate the movement of the boundary, and the calculation was relterated.

The results of the program developed were authenticated by comparison to an experiment of Ref. 6. When compared to the pseudo-Gümbel boundary conditions (Ref. 4), the results predicted a significant difference in the computed load capacity (up to 20 percent). Furthermore, it was found that the size, life, and location of the cavitation bubble were considerably affected by imposing the pseudo-Gümbel boundary conditions.

\section{Fluid Velocity Under Dynamic Loading}

Consider the bearing geometry shown in fig. 1. As shown, the minimum-film thickness rotates clockwise around the bearing at a whirl frequency of $\gamma$. Jacobson and Hamrock (Ref. 2) show that from this diagram $\gamma$ can be evaluated 


$$
r=\tan ^{-1} \frac{\varepsilon_{d} \sin \left(\omega_{d} t\right)}{\varepsilon_{s}+\varepsilon_{d} \cos \left(\omega_{d} t\right)}
$$

so that

$$
\dot{\gamma}=\frac{\varepsilon_{d}\left[\varepsilon_{s} \cos \left(\omega_{d} t\right)+\varepsilon_{d}\right] \omega_{d}}{\varepsilon_{s}^{2}+\varepsilon_{d}^{2}+2 \varepsilon_{s} \varepsilon_{d} \cos \left(\omega_{d} t\right)}
$$

The sliding velocity of the journal is

$$
U=\left(\omega_{S}-2 \dot{\gamma}\right) R
$$

Film Thickness and Deformation

The film thickness for a bearing having a rigid liner can be given as

$$
h=\Delta R-e \cos \varphi
$$

where the total eccentricity e defined as the instantaneous distance between $O_{b}$ and $O_{j}$ is

$$
e=\frac{e_{d} \sin \left(\omega_{d} t\right)}{\sin \gamma}
$$

If one considers deformation of the bearing surface, the film thickness can be written as:

$$
h=\Delta R-e \cos \varphi+\delta
$$

or normalizing with respect to the clearance, $\Delta R$, we have

$$
H=1-\varepsilon \cos \varphi+\Delta
$$

where $\delta$ represents the radial defiection and $\Delta=\delta / \Delta R$.

This study considers only lst order effects of the elastic deflection of a soft bearing lijner on damper performance. These deflections are calculated using the assumptions adopted by Higginson (Ref, 8) for a soft liner material rigidly enclosed, i.e.,

$$
\Delta=B \bar{p}
$$

This simple expression can be derived by assuming the liner to be an elastic material that deforms linearly due to local pressures under conditions of plane strain. Accordingly, the parameter $B$ can be shown to be 


$$
\begin{gathered}
B=\frac{6 n \omega_{d} t}{(\Delta R / R)^{3} E R}\left(1-\frac{2 \sigma^{2}}{1-\sigma}\right) \\
\bar{p}=\frac{(\Delta R / R)^{2} p}{6 n \omega_{d}}
\end{gathered}
$$

Since the film thickness is directly proportional to the local pressure, the solution of Eq. (1) requires nonlinear techniques. An iteration procedure was introduced that required the sum of the pressure field to deviate by no more than 0.05 percent due to iterations in film thickness.

GEOMETRY AND OPERATING CONDITIONS

The damper (bearing) simulated in this study is based on an experimental study of a journal-bearing squeeze film damper submerged in Dexron lubricant (Ref. 7). The range of operating conditions are listed in Table I.

\section{RESULTS AND DISCUSSION \\ Effect of Flexibility on Cavitation}

The effect of flexibility on vapour cavitation was studied for a journal undergoing noncentered circular whirl. Three liner materials were used in this investigation to achieve the range of flexibilities. These materials were steel, polymethylmethacrylate (PMMA) and polytetrafluorethylene (PTFE). Table II lists these materials and their elastic constants in order of increasing flexibility for a range of different viscosities. The percent of time that a vapor bubble is predicted for one full orbit of the journal is listed under "Bubble life." To the right of this column are listed bubble inception and collapse. These values are given in milliseconds of time relative to the moment that the minimum eccentricity of the orbit occurs. Thus at startup, $\varepsilon=0.1$ and $t=0.0$. The orbital period of the journal is 67.7 ms during which time the eccentricity ratio varies between 0.1 and 0.9 . Note that as the viscosity increases the bubble life increases to the extent 
that cavitation exists throughout the entire cycle for both the steel liner and the PTFE liner. However, the effect of increased flexibility retards the sensitivity of bubble life to increases in viscosity. This appears to be attributed to the mechanism leading to the collapse of the bubble. From the table we see that for the steel liner the bubble collapse is delayed as viscosity is increased. But for the PTFE liner the bubble collapse appears insensitive to viscosity changes.

From the standpoint of a viscous damper, it is logical that cavitation can only serve to decrease the damping characteristics. The above results lead one to infer that as the viscosity is increased better damping characteristics can be achieved using a PTFE liner over a steel liner for a limited range of viscosities. Further, increasing the viscosity should give better damping characteristics, but the accompanying increased bubble life could deter that desirable effect.

\section{Cavitation and Pressure Distribution}

Figures 2 and 3 fllustrate the responding pressure variation to the motion of the shaft undergoing noncentered circular whirl for two contrasting situations. Figure 2 represents the events taking place for a rigid (steel) liner with parameter $B=0.000038$. Figure 3 contrasts those same events for a soft (PTFE) liner having $B=0.004440$. In both cases, the viscosity was a constant $0.099 \mathrm{~Pa} \cdot 5$. In each figure, part (a) lllustrates the starting position (i.e., $\varepsilon=0.1$ ). Parts (a) to (f) depict several key events in the clockwise circular motion of the journal center within the bearing.

Figure $2(a)$ represents the position of the journal within the housing and the associated pressure distribution at the instant that the eccentricity is at a minimum. The dark oblong region indicates the shape and position of a vapor bubble downstream of the minimum-film line. The position of the bubble within the small clearance space of the journal bearing is also indicated. At 
this particular instant the tendency of the pressure flow along the side of the bubble to cause the bubble to collapse becomes greater since it is proportional to $h^{3}$. The journal center moves in a clockwise orbit from Figs. $2(a)$ to (b) (nearly one-tenth of a revolution). While the eccentricity is increasing, the minimum film is decreasing which gives rise to the squeeze action in the vicinity of the minimum-film line. A slight rise in the pressure field can be observed there. Note in Fig. $2(b)$ the collapse of the bubble occurs $\sim 6$ ms later than in $3(b)$.

Cavitation is absent from Fig. 2(b) to (c). In Fig. 2(c), a new cavitation bubble appears, and the pressure generation in the region of the minimum-film line becomes significantly large because of the squeeze effect taking place there. Figure $2(d)$ represents the configuration of the bearing when the maximum pressure occurs. Note that this happens before the maximum eccentricity is reached.

Comparing Fig. 2(d) with Fig. $3(d)$ we see that the peak pressure occurs at essentially the same eccentricity (i.e., 0.88) but that the shape and magnitude of the pressures are markedly different. For the PTFE liner in Fig. $3(d)$ the peak pressure is 51 percent lower than the rigid liner of Fig. $2(d)$. Also it is illustrating the effect of the displacement in the high pressure region producing a flattening shape along the axial direction.

Figure $2(e)$ represents the end of the squeeze cycle and the beginning of the separation cycle. Now the minimum film begins to increase which creates a suction effect, an accompanying growth in the bubble, and a dissipation of the pressure hump noted in Fig. $2(f)$. It is interesting to note that the eccentricity is the same (0.88) for Figs. $2(d)$ and (f). The drastic difference in the pressure plot is a result of the squeeze velocity having opposite signs in the two situations. The minimum-film thickness continues to 
increase as it moves in a clockwise direction. The representation shown in Fig. $2(a)$ is repeated as are the representations for each succeeding orbit. Dimensionless Load Capacity Versus Eccentricity

Figure 4 represents the dimensionless load capacity $(\bar{w})$ versus eccentricity ratio $(\varepsilon)$ for different $B$ parameters. By presenting the results using dimensionless load, (i.e., duty parameter) the effect of viscosity is normalized out and one can focus on the relative elastic effects. The predominant effect to note in this figure is that as $B$ increases the peak dimensionless load decreases. These curves were generated for two different liner materials (i.e., steel and PTFE). The steel liner $(B=0.000025$ ) is represented with the curve having the maximum peak load. The other two curves were generated with PTFE as the liner material. The reduced dimensionless peak load for the PTFE material is a result of larger deflections due to the local pressures. Thus higher film thickness in the region of higher pressures result in a pressure relaxation and consequent reduction in load capacity. This is a commonly observed result.

\section{CONCLUSIONS}

A study of the effect of bearing liner elasticity on vapor cavitation and damper performance under dynamic conditions is presented. The motion considered in this study was that of a journal undergoing noncentered circular whirl. The bearing liners considered were steel, polymethylmethacrylate, and polytetrafluorethylene. The analysis was performed using the Elrod algorithm for an isoviscous lubricant. A range of viscosities were investigated (i.e., $0.066 \mathrm{~Pa} \cdot \mathrm{s}$ to $0.66 \mathrm{~Pa} \cdot \mathrm{s}$ ) to help elucidate the effect of liner elasticity. The study revealed the following:

1. For the low values of viscosity in this study there was no effect on cavitation due to increasing the flexibility by two orders of magnitude. As 
viscosity was increased the effect of flexibility became apparent by inhibiting the increase in bubble life.

2. Increasing the viscosity led to an increase in bubble life for all liner materials considered.

3. As the viscosity is increased, better damping characteristics can be achieved using a PTFE liner over a steel liner for a limited range of viscosities.

4. Increasing the flexiblility of the bearing liner results in a reduction and flattening of pressures along the axial length of the bearing.

5. As the parameter $B$ increases the peak dimensionless load decreases. This parameter essentially normalizes out the effect of viscosity.

\section{REFERENCES}

1. B.0. Jacobson, and B.J. Hamrock, "High-Speed Motion Picture Camera Experiments of Cavitation in Dynamically Loaded Journal Bearings," J. Lubr. Technol., 105 (1983) 446-452.

2. B.0. Jacobson, and B.J. Hamrock, "Vapor Cavitation in Dynamically Loaded Journal Bearings," Proc. Inst. Mech. Eng. London, C206 (1983) 133-140.

3. H.G. Elrod, "A Cavitation Algorithm," J. Lubr. Technol., 103 (1981) 350-354 .

4. D.E. Brewe, "Theoretical Modeling of the Vapor Cavitation in Dynamically Loaded Journal Bearings," USA-AVSCOM Rep. TR 85-C-15 and NASA Rep. TM-87076, 1985 (also J. Tribol., 108 (1986) 628-638).

5. K.0. Olsson, "On Hydrodynamic Lubrication with Special Reference to Nonstationary Cavitation," Chalmers University of Technology, Goteborg, 1974.

6. B. Jakobson, and L. Floberg, "The Finite Journal Bearing Considering Vaporization," Chalmers Tekniska Hoegskolas Handlingar, Vol. 190, 1957, pp. $1-116$. 
7. D.E. Brewe, B.J. Hamrock, and B. Jacobson, "Theoretical and Experimental Comparison of Vapor Cavitation in Dynamically Loaded Journal Bearings," NASA Rep. TM-87121 and USAAVSCOM Rep. TR-85-C-19, 1985.

8. G.R. Higginson, "The Theoretical Effects of Elastic Deformation of the Bearing Liner on Journal Bearing Performance, in Elastohydrodynamic Lubrication," Proceedings of the Symposium, Institution of Mechanical Engineers, London, Vol. 180, Part 3B, 1965. pp. 31-38.

9. D. Dowson, and C.M. Taylor, "Elastohydrostatic Lubrication of Circular Plate Thrust Bearings," J. Lubr. Technol., 89 (1967) 237-244.

10. H.D. Conway, and H.C. Lee, "The Analysis of the Lubrication of a Flexible Journal Bearing," J. Lubr. Technol., 97 (1975) 599-604.

11. H.D. Conway, and P.A. Engel, "The Elastohydrodynamic Lubrication of a Thin Layer," J. Lubr. Technol., 95, (1973) 381-385.

12. L.R.K. Nilsson, "The Influence of Bearing Flexibility on the Dynamic Performance of Radial Oll Film Bearings," in D. Dowson, C.M. Taylor, M. Godet and D. Berthe (eds.), Elastohydrodynamics and Related Topics, Mechanical Engineering Publications, London, 1978, pp. 311-319.

13. V. Castell1, G.K. Rightmire, and D.D. Fuller, "On the Analytical and Experimental Investigation of a Hydrostatic, Axisymmetric Compliant-Surface Thrust Bearing," J. Lubr. Technol., 89 (1967) 510-520.

14. T.E. Carl, "The Experimental Investigation of a Cylindrical Journal Bearing Under Constant and Sinusoidal Loading," in Lubrication and Wear, Second Convention, Proceedings, Institute of Mechanical Engineers, London, E. paper 19, 1964, p. 100.

15. C.J. Hooke, D.K. Brighton, and J.P. O'Donoghue, "The Effect of Elastic Distorsions on the Performance of Thin Shell Bearings," in Journal Bearings for Reciprocating and Turbo Machinery, Proceedings, Institution of Mechanical Engineers, London, Vol. 181, Part 3B, 1966-67, pp. 63-69. 
16. J. O'Donoghue, D.K. Brighton, and C.J.K. Hooke, "The Effect of Elastic Distortion on Journal Bearing Performance," J. Lubr. Technol., 89 (1967) 409-417.

17. M.J. Braun, and J.D. Dougherty, "Hydrodynamic Analys is and Fluid-Solid Interaction Effects on the Behavior of a Compliant Wall (Thick) Journal Bearing. Part 2: Results," Presented at ASME-STLE Joint Tribology Conference, Oct. 17-19, 1988, Baltimore, MD. 
TABLE I. - OPERATING CONDITIONS

\begin{tabular}{|c|c|c|c|c|c|c|c|c|c|c|c|c|c|c|c|}
\hline$\Delta R, \mathfrak{m}$ & . . & . & - & • & & & & & & & & & & , & $\therefore \quad 5.0 \times 10^{-4}$ \\
\hline$R, \pi$. . & - $\cdot$ & · . & • & 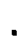 & & & & & & & • & & & • & 0.0425 \\
\hline$L / D$ & * . & - . & - & • & 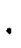 & 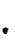 & . & 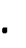 & 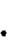 & & . . & 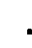 & & & .... 1.0 \\
\hline . . & . . & . & . & . & & & & & & & $\cdot$ & 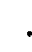 & & - & 0.1 to 0.9 \\
\hline$\omega_{d}, \mathrm{rad} / \mathrm{s}$ & & • & . & & & & & & & & & & & & . . -92.7 \\
\hline$\omega_{s}, \mathrm{rad} / \mathrm{s}$ & & * & . & & & & & & & & & & & $\cdot$ &... .0 \\
\hline$B, N / m^{2}$ & , & & . & & & & & & & & & & & & $1.72 \times 10^{9}$ \\
\hline$P_{a}, N / m^{2}$ & . & & & & & & & & & & & & & & $1.0133 \times 10^{5}$ \\
\hline$P_{C}, N / m^{2}$ & . & 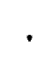 & ${ }^{\circ}$ & " & & & & & & & & & & 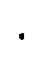 &... .0 .0 \\
\hline
\end{tabular}

TABLE II. - EFFECT OF FLEXIBILITY ON CAVITATION

\begin{tabular}{|c|c|c|c|c|c|c|c|}
\hline \multirow[t]{2}{*}{$\begin{array}{l}\text { Liner } \\
\text { material }\end{array}$} & \multicolumn{2}{|c|}{ Material constants } & \multirow[t]{2}{*}{$\begin{array}{l}\text { Viscosity, } \\
\eta(P a S)\end{array}$} & \multirow[t]{2}{*}{$B \times 10^{-3}$} & \multirow[t]{2}{*}{$\begin{array}{l}\text { Bubble life, } \\
\text { percent cycle }\end{array}$} & \multirow[t]{2}{*}{$\begin{array}{c}\text { Inception, } \\
\text { ms }\end{array}$} & \multirow[t]{2}{*}{$\begin{array}{c}\text { Collapse, } \\
\text { ms }\end{array}$} \\
\hline & 0 & $E(G P a)$ & & & & & \\
\hline Stee 1 & 0.30 & 206.0 & $\begin{array}{l}0.066 \\
.077 \\
.099 \\
.264 \\
.660\end{array}$ & $\begin{array}{r}0.025 \\
.029 \\
.038 \\
.100 \\
.250\end{array}$ & $\begin{array}{r}77.13 \\
81.71 \\
90.55 \\
100.00 \\
100.00\end{array}$ & \begin{tabular}{l}
22.74 \\
21.74 \\
19.44 \\
\hdashline.-- \\
.--
\end{tabular} & $\begin{array}{r}7.23 \\
9.34 \\
13.04 \\
--- \\
---\end{array}$ \\
\hline PMMA & 0.40 & 2.76 & 0.066 & 1.160 & 76.73 & 22.80 & 7.03 \\
\hline PTFE & 0.46 & 0.50 & $\begin{array}{l}0.066 \\
.077 \\
.099 \\
.264 \\
.660\end{array}$ & $\begin{array}{r}2.960 \\
3.454 \\
4.440 \\
11.841 \\
29.602\end{array}$ & $\begin{array}{r}76.25 \\
77.87 \\
81.26 \\
100.00 \\
100.00\end{array}$ & $\begin{array}{l}23.04 \\
21.74 \\
19.64 \\
-.- \\
\end{array}$ & $\begin{array}{r}6.94 \\
6.94 \\
6.94 \\
- \\
\end{array}$ \\
\hline
\end{tabular}




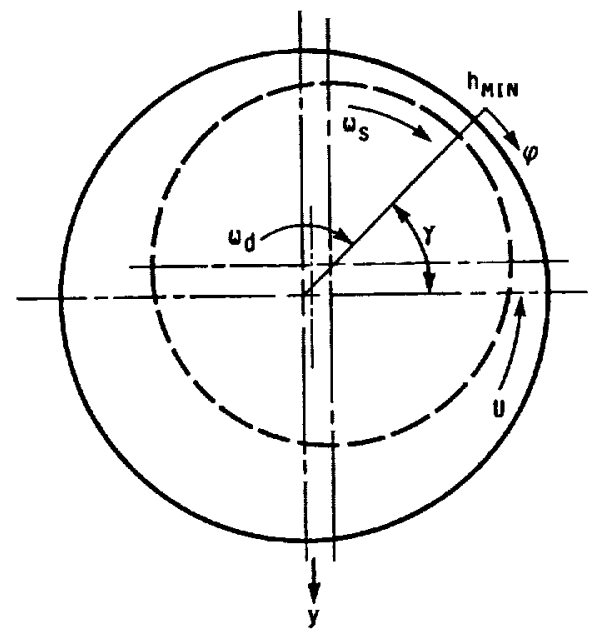

(a)

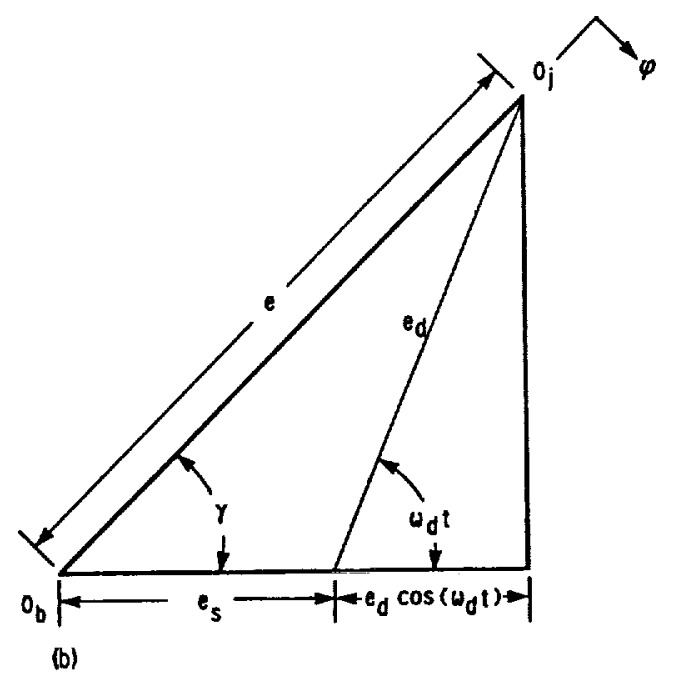

FigURE 1. - JoURnal beARing configuration. 


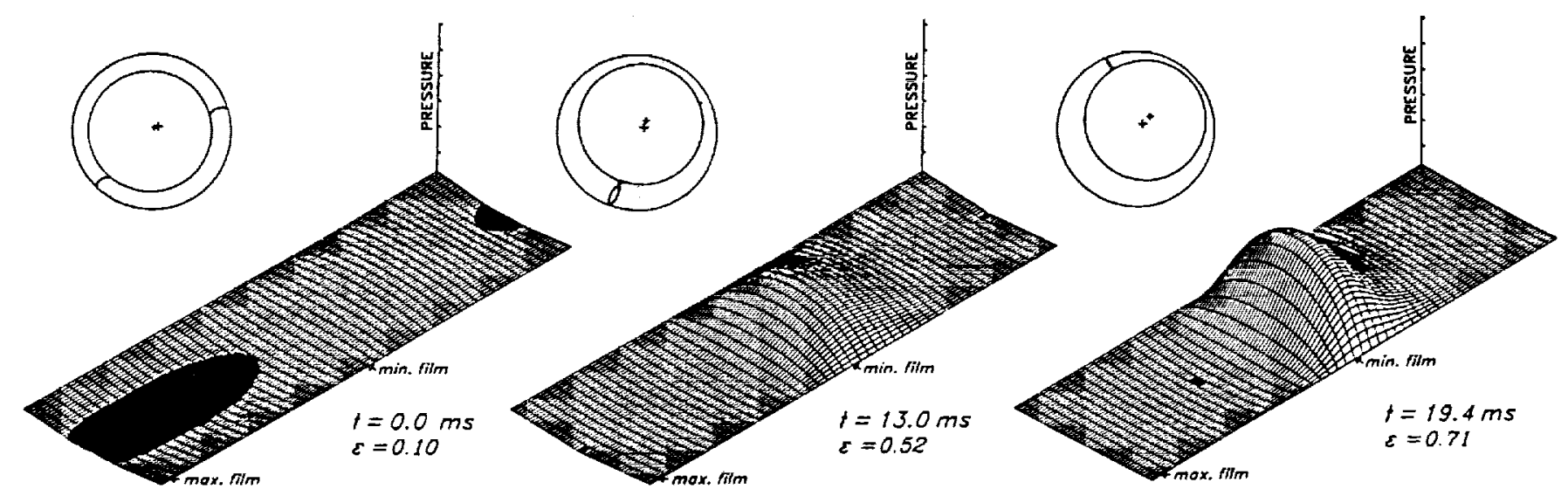

(a) ROTOR AT MAXIMUM SEPARATON.

(b) CAVITATION BUBBLE COLLAPSES.

(c) INCIPIENT CAVITATION.

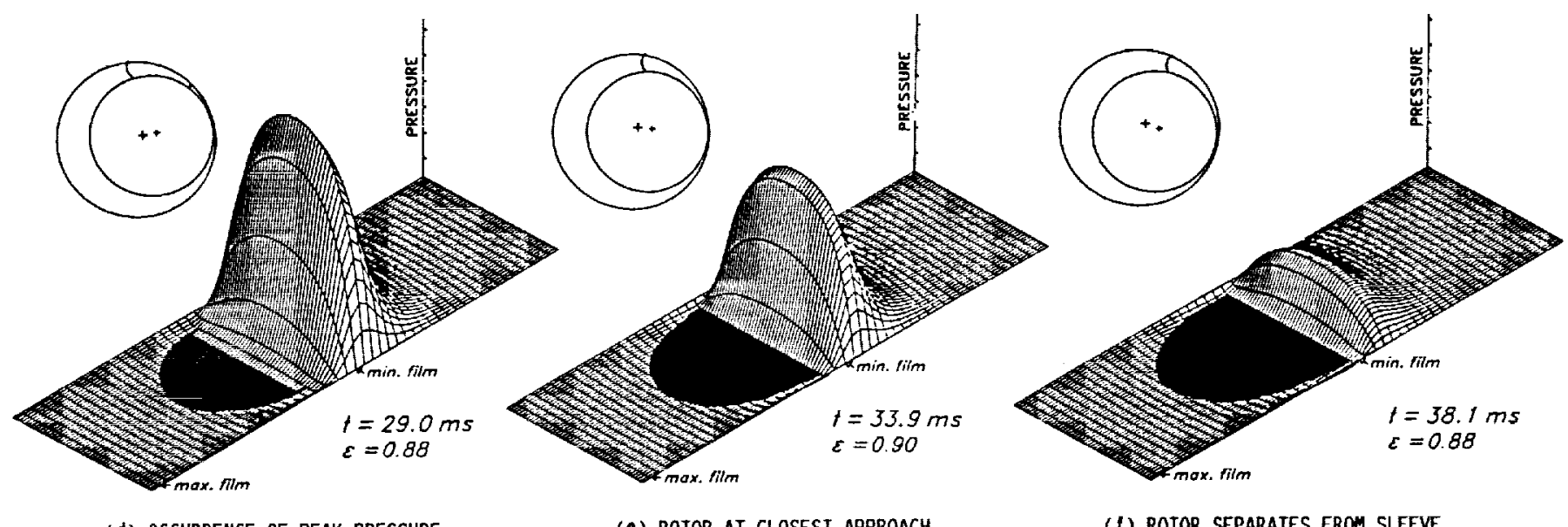

(d) OCCURRENCE OF PEAK PRESSURE.

(b) ROTOR AT CLOSEST APPROACH.

(1) ROTOR SEPARATES FROM SLEEVE.

FIGURE 2. - PRESSURE DISTRIBUTION AND BEARING CONFIGURATION (RIGID LINER, B $=0.000038$ ) FOR A FULL PERIOD OF SHAFT WHIRL. USING ELROD'S ALGORITHM. THE FIGURES $(a-f)$ VIEMED IN CLOCKWISE ORDER ARE CONSECUTIVE IN TIME.

\author{
ORIGINAL PAGE \\ BLACK AND WHITE PHOTOGRAPH
}




\section{ORIGINAL PAGE \\ BLACK AND WHITE PHOTOGRAPH}

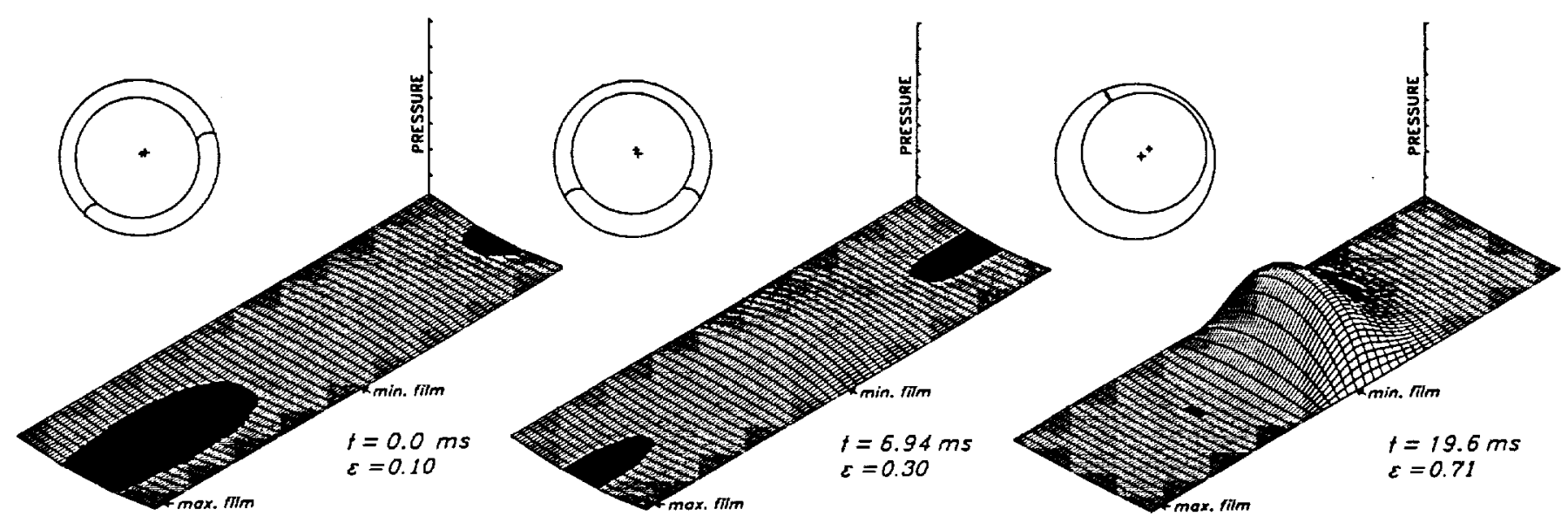

(a) ROTOR AT MAXIMUN SEPARATION.

(b) CAVITATION BUBBLE COLLAPSES.

(c) INCIPIENT CAVITATION.

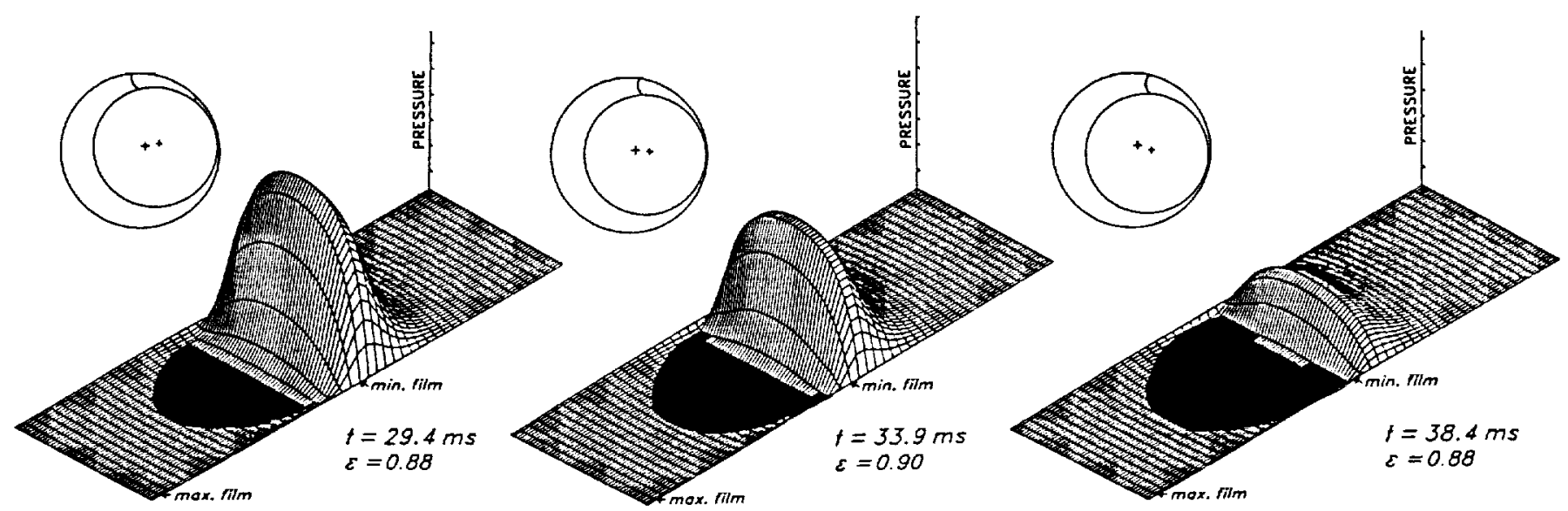

(d) OCCURRENCE OF PEAK PRESSURE.

(e) ROTOR AT CLOSEST APPROACH.

(1) ROTOR SEPARATES FROM SLEEVE.

FIGURE 3. - PRESSURE DISTRIBUTION AND BEARING CONFIÜURATION (PTFE LINER, B $=0.004440$ ) FOR A FULL PERIOD OF SHAFT WHIRL, USING ELROD'S ALGORITHM. THE FIGURES $(a-f)$ VIEMED IN CLOCKUISE ORDER ARE CONSECUTIVE IN TIME. 


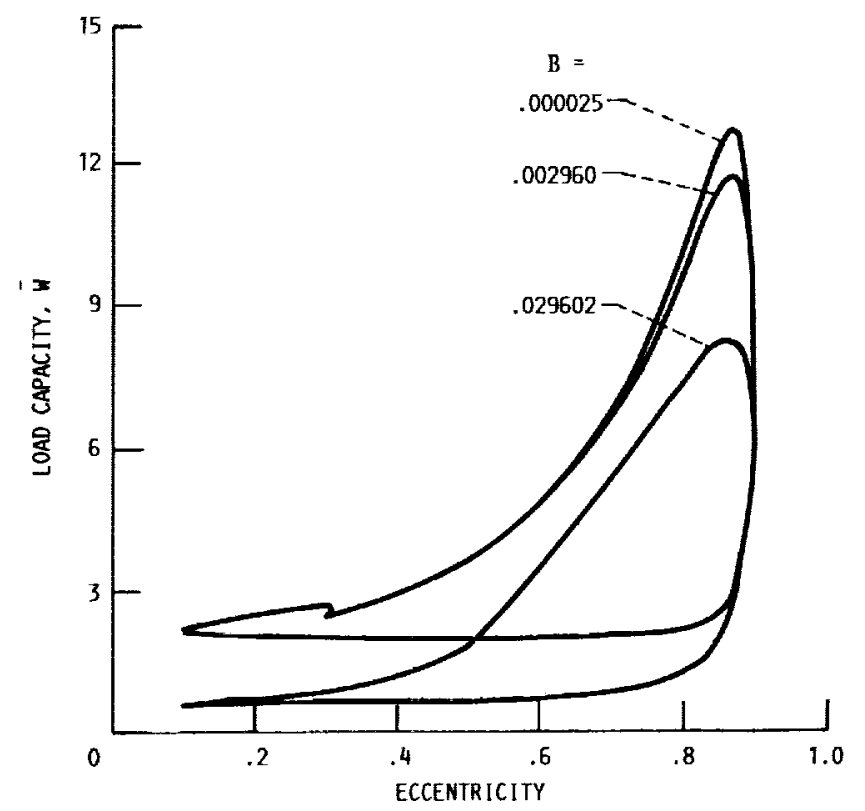

FIGURE 4. - DIMENSIONLESS LOAD CAPACITY VERSUS ECCENTRICITY. 


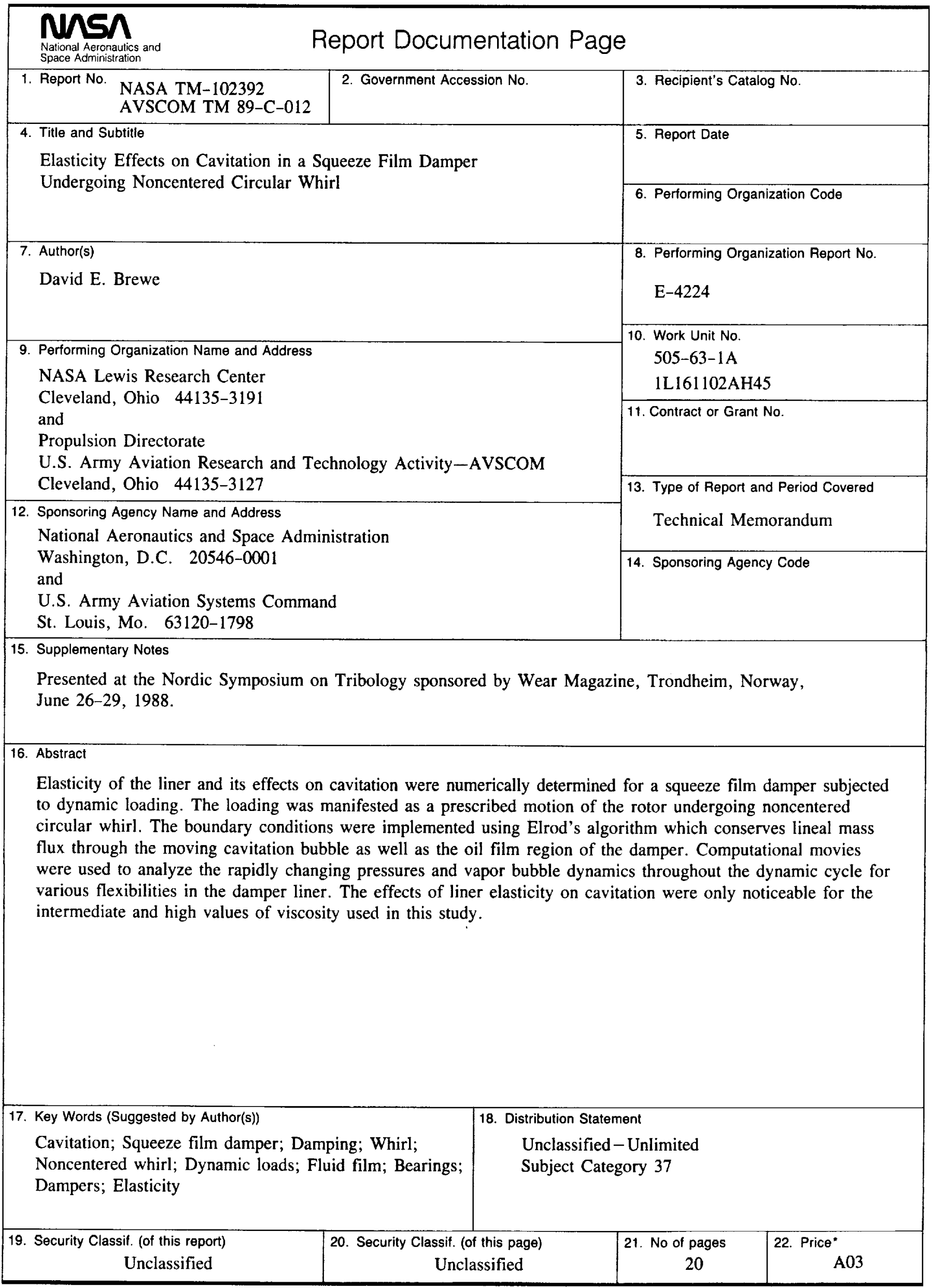


